\title{
The Relationship between Part 121 Pilots’ Age and Accident Rates
}

\author{
Michael A. Gallo and Arthur Clauter \\ Florida Institute of Technology
}

\begin{abstract}
This ex post facto study examined the relationship between Part 121 pilots' age and accident rate per 1000 flight hours using data from Aviation Safety Information Analysis and Sharing(ASIAS) for the 14-year period 1998-2011. Of the 970 aviation events reported, 267 met our definition of an accident, which followed the FAA's definition but also included a more restrictive requirement that the accident had to be related to pilot error. Of the 267 aviation accidents, 97 (36\%) had missing age or flight hours data, which reduced the sample size to $N=170$. Regression analyses confirmed neither a significant bivariate linear relationship, $r^{2}=.007, F(1,35)=0.26, \quad p=.6127$, nor a quadratic relationship, $R^{2}=.102, F(2,34)=1.93, p=.1601$, between pilot age and accident rate. Furthermore, although the increment in explained variance $\left(s r^{2}\right)$ between the linear and quadratic models was .095 , this increment was not significant, $F(1,35)=3.687, p=$ .0630. Findings indicate that pilot age was not a significant predictor of aviation accident rates with respect to accidents that involved pilot error. A recommendation for practice is for the FAA to reconsider the age restriction for Part 121 pilots, and for the NTSB to strive for data completeness and integrity by ensuring that all the data are collected and included in their investigation reports.
\end{abstract}

\section{Introduction and Background}

\section{The Age 60 Rule}

One of the most controversial issues within the airline safety community is the relationship between pilots' age and airline accidents. This issue first emerged more than 50 years ago and led to the "Age 60 Rule," which was enacted in December 1959 and became effective March 1960 by the Federal Aviation Administration (FAA). The Age 60 Rule prohibited air carriers "from using the services of any person as a pilot, and prohibits any person from serving as a pilot, on an airplane engaged in operations under part 121 if that person has reached his or her 60th birthday" (FAA, 2009, p. 34229). Part 121 operations include large commercial passenger aircraft, smaller propeller aircraft with 10 or more passenger seats, and common carriage operations of all-cargo aircraft with a payload capacity of 7500 pounds.

The Age 60 Rule was enacted without the benefit of medical or scientific studies and without public comment. Since then, it was expanded from part 121 to include part 135 operations based mostly on studies conducted by Broach (1999), Golaszewski (1983, 1991, \&1993), and Kay et al. (1994). Although there is considerable evidence that age is 
neither a valid nor reliable predictor of a part 121 pilot's ability to fly an aircraft safely, the FAA has reasoned there is a greater likelihood of accidents occurring for older pilots because of the association between declining cognitive ability and age (International Brotherhood of Teamsters, 2005). The rule also "has been the focus of numerous inconclusive studies, several subsequent rulemaking proceedings, many court battles, and occasional legislative attempts to overturn or modify it” (International Brotherhood of Teamsters, 2005, p. 2).

\section{Studies Refuting the Age Effect}

Mohler, Bedell, Ross, and Veregge (1967) conducted one of the earliest studies on this topic by examining the relationship between accident rate and pilot age. Mohler et al. separated the data into different levels of pilot certification-student, private, commercial, and air transport - and partitioned the accidents by age groups of 16-29, 3044, 45-59, and 60 and over, respectively, for 450,494 certified aviation pilots in all categories mid-year 1965. They then calculated accident rate using the number of pilots in each age group and category with respect to the number of accidents per 10,000 pilots. Mohler et al. reported that the overall accident rate of the age 60 and older group was 110 accidents per 10,000 pilots 60 years old or older. By comparison, the accident rate of the other age groups was 106 for the 16-29 group, 121 for the 30-44group, and 100 for the 45-59 group. When focused strictly on the air transport category of pilots, Mohler et al. reported the following accident rates: 298for the 16-29 group, 118 for the 30-44group, 104for the 45-59 group, and 104 for the 60 and over group. Based on the results of a Chisquare analysis, Mohler et al. indicated that pilots over 60 years old "were essentially as safe as their younger colleagues" (p.6).

Broach (2000) re-analyzed the data from the 1999 Chicago Tribute study, which reported that "older pilots were '....among the safest in the skies'” (p. 2) based on an analysis of 450 "incidents" between January 1, 1990 and June 11, 1999. According to Broach (p. 4), "the original Tribune analysis underestimated the actual ATP population across the 9.5 years by almost 250,000 pilots." Based on his re-analysis, Broach concluded there were no significant differences in the accident/incident rates among different age groups.

Despite the arguments put forth claiming pilots' likelihood for sudden incapacitation after the age of 60 years was greater than their younger counterparts, Li et al. (2003) uncovered the opposite based on 3,306 commuter air carrier and air taxi pilots aged 4554 years in 1987. A follow up study conducted 10 years later revealed that of 12.9 million aggregate flight hours, there were 66 crashes, or about 5.1 crashes per 1 million flight hours. According to Li et al., "Crash risk remained fairly stable as the pilots aged from their late forties to their late fifties. Flight experience, as measured by total flight time at baseline, showed a significant protective effect against the risk of crash involvement" (p. 874). Li et al.'s findings were consistent with Broach's (2000) findings. Both studies showed the youngest and less-experienced pilots having the greatest risk or accident rate. 
The second age group and experience level had the lowest risk, and the third age group or experience level was slightly higher than the second. Finally, the eldest pilots (those who were 50-59 years of age or had more than 15,000 flight hours) had a slightly lower risk or accident rate than those in the third eldest group.

\section{Studies Supporting the Age Effect}

In a series of four reports, Broach, Joseph, and Schroeder (2003) purposely focused on pilot age and accident rates based on accident data provided by the National Transportation Safety Board (NTSB) for the period 1988 through 1997. They defined accident rate as the ratio of the total number of accidents (fatal and nonfatal) to annual hours flown by air transport pilots (ATP), which included part 121 and part 135 pilots. Broach et al. estimated the number of annual hours from medical examination records, which were extracted from the FAA Comprehensive Airman Information System.

Broach et al. (2003) conducted three separate analyses based on different age categories. The most relevant to the current study involved non-overlapping age groups for 5-year periods: LE29, 30-34, 35-39, 40-44, 45-49, 50-54, 55-59, and 60-63. Broach et al. reported a U-shaped distribution between accident rate and age groups: For the younger and older year's age groups, accident rates were higher than for the middle year's age groups. They also indicated that the accident rate for the 60-63 age groups was statistically greater than that for 55- or 56-59-year-old pilots, and that age was statistically significant. Broach et al. concluded that their findings suggested part 121 and part 135 accidents based on annual flight hours were related to age.

\section{Recent Developments}

In a review of U.S. civil aviation accidents from January 1, 2007 to December 31, 2009, the National Transportation Safety Board (2011) reported there were 4,958 aviation accidents that resulted in 1,641 fatalities. Of these totals, though, there were 86 , or $1.7 \%$, accidents that resulted in 56, or 3.4\%, fatalities involving part 121 pilots. The vast majority of accidents and fatalities were attributed to part 91, general aviation pilots. According to NTSB, "Part 121 accident rates ... have declined from 2000 to 2009 (and) between 2007 and 2009, turbulence encounters during the en route phase of flight was the most common defining event for Part 121 accidents, followed by on-ground collisions between aircraft” (p. 1).

In December 2007, then-President Bush signed the "Fair Treatment for Experienced Pilots Act," which increased the mandatory retirement age for part 121 pilots to 65. It has now been 5 years since this Act took effect and the first wave of part 121 pilots who were 60 years old in 2007 began mandatory retirement. Independent of this event, there have been no studies that have examined pilot age and accident rates since Broach et al. (2003), which examined data from 1988 to 1997. 


\section{Summary of Past Studies}

The literature reviewed here shows a mix of findings with respect to pilot age and aviation accidents. Some studies such as Mohler et al. (1967), Broach (2000), and Li et al. (2003) indicate that older pilots are not more likely to be involved in accidents whereas other studies such as Broach et al. (2003) refute this claim. One of the concerns with all of these studies is they are not always focusing on data involving part 121 pilots, which is the only group targeted by FAA for the Age 60 Rule. One of the biggest concerns, though, is the data being used for these analyses are neither necessarily accurate nor complete. For example, Broach et al. estimated pilots' annual flight hours, combined part 121 and 135 pilot data, and commented on the limited availability of data. Furthermore, the last fully reported study involving Part 121 pilots' age and accident rates was Broach et al., which involved data that was collected more than 15 years ago.

\section{Purpose Statement and Operational Definitions}

The purpose of the current study was to address some of the issues from past studies and to extend the current discussion of the Age 60 Rule by including more recent data. The current study augmented Broach et al. (2003) by examining part 121 U.S. airlines pilots' age and accident statistics for the 14-year period January 1, 1998 to December 31, 2011. This targeted period also included data from 2008-2011, which for the first time since the Age 60 Rule took effect includes part 121 pilots older than 60. Because the scope of this study involved aviation accidents, the following definitions are provided from the Federal Aviation Administration (see FAA Transportation Definitions, 1988):

Aircraft accident means an occurrence associated with the operation of an aircraft which takes place between the time any person boards the aircraft with the intention of flight and all such persons have disembarked, and in which any person suffers death or serious injury, or in which the aircraft receives substantial damage.

Fatal injury means any injury that results in death within 30 days of the accident.

Serious injury means any injury which: (1) Requires hospitalization for more than 48 hours, commencing within 7 days from the date of the injury was received; (2) results in a fracture of any bone (except simple fractures of fingers, toes, or nose); (3) causes severe hemorrhages, nerve, muscle, or tendon damage; (4) involves any internal organ; or (5) involves second- or third-degree burns, or any burns affecting more than 5 percent of the body surface.

Substantial damage means damage or failure which adversely affects the structural strength, performance, or flight characteristics of the aircraft, and which would normally require major repair or replacement of the affected component. 
Engine failure or damage limited to an engine if only one engine fails or is damaged, bent fairings or cowling, dented skin, small punctured holes in the skin or fabric, ground damage to rotor or propeller blades, and damage to landing gear, wheels, tires, flaps, engine accessories, brakes, or wingtips are not considered "substantial damage" for the purpose of this part.

Incident means an occurrence other than an accident, associated with the operation of an aircraft, which affects or could affect the safety of operations.

For the current study, we used a more restrictive definition of an aircraft accident by including only those accidents that were the result of pilot error and could have been prevented by the pilots. To make the distinction between the FAA's definition and our more restrictive definition, we used the NTSB's assessment of the probable cause(s) of an accident. For example, in event record 20040319X00351, the NTSB determined the probable cause to be: "The captain's improper decision due to his attempt to taxi back onto the runway after coming to a stop in the grass, and the resulting collapse of nose landing gear” (NTSB, 2004, “NTSB Identification: CHI04LA086”). As a result, this event was considered an accident by our more restrictive definition and was included in our analysis. On the other hand, in event record 20001212X20714, the NTSB determined the probable cause to be "The tug operator's inadequate visual lookout" (NTSB, 2000, "NTSB Identification: NYC00LA086"), which was not pilot-related, and therefore this event was not included in our analysis.

\section{Methodology}

The population for this study was all aviation events (incidents and accidents) involving Part 121 operations between January 1, 1998 and December 31, 2011. We targeted this population because the last full study that examined the relationship between Part 121 pilots and accident rate (Broach et al., 2003) used data between 1988 and 1997. Our sampling strategy was purposive: We selected only those events that were consistent with the FAA's definition of an accident but also met our additional criterion where the accident was a consequence of pilot error. This sampling strategy was appropriate because we were seeking a sample that would be typical, or representative, of Part 121 pilots who were involved in aircraft accidents judged to be due to pilot error.

To acquire the data set, we submitted an e-mail request to an Aviation Safety Information Analysis and Sharing (ASIAS) analyst at ASIAS@faa.gov. The initial data set we received consisted of 970 events. We then reviewed each event by entering the event ID in a Google search and reading the descriptions. As noted earlier, we focused on what the NTSB determined to be the probable cause of the event. Of the 970 events, 267 satisfied our restrictive definition of an accident, but only 170 contained complete data for pilots' age and aggregate flight hours. Thus, the final sample size was $N=170$. When we inquired about the missing data, we received the following reply from J. Werner, aviation safety analyst for the FAA (personal communications, October 19, 2012): 
"Those data are missing either because they were not known at the time of investigation or the investigator did not enter the data into the fields.”

The primary research question that guided the study was: "What is the relationship between pilot age and accident rate under FAA part 121 operations?” Depending on the context, accident rate was defined as either per 1,000 or 10,000 flight hours. The corresponding research hypothesis was that pilot age is not related to aviation accident rates. We used a correlational research methodology because the sample consisted of a single group (part 121 pilots) and multiple measures (pilots' age, total flight hours, accident rate). Because correlational studies examine relationships among variables without any manipulation or control, the reader is cautioned not to infer any cause-andeffect relationship from the findings.

\section{Data Analysis}

\section{Descriptive Statistics}

A summary of the number of events and number of accidents organized by year is provided in Table 1 and pictorially illustrated in Figure 1. As noted earlier and illustrated in Table 1, there were 970 events during the 14-year period 1998-2011 of which 267 were considered accidents by our more restrictive definition. With the exception of 2002, the number of events during each year increased steadily from 1998 to 2003, and peaked at 106. There was no consistent pattern, though, in the number of events from 2004 to 2011. Overall, the mean number of events for the 14-year period was $M=69.3$ (SD = 17.98, Range: 53 to 106). It is interesting to note that the fewest number of events occurred in 2011.

The number of accidents that were extracted from the events data for their respected year showed a different picture. Of the 54 events that occurred in 1998, none were considered accidents by our restrictive definition. Unlike the number of events, which increased steadily from 1998 to 2003, the number of accidents essentially decreased from 1999 to 2004. From 2005 to 2011, though, there was no consistent pattern between year

and number of accidents. Nevertheless, the accident frequency for this latter period was relatively low. Overall, the mean number of accidents for the 14-year period was $M=$ 19.1 ( $S D=10.1$, Range: 0 to 31), with the fewest number of accidents occurring in 2010 and 2011. 
Table 1

Summary of Number of Events and Accidents

\begin{tabular}{ccc}
\hline $\begin{array}{c}\text { Year } \\
\text { of Event }\end{array}$ & $\begin{array}{c}\text { Number } \\
\text { of Events }\end{array}$ & $\begin{array}{c}\text { Number } \\
\text { of Accidents }\end{array}$ \\
\hline 1998 & 54 & 0 \\
1999 & 56 & 31 \\
2000 & 70 & 31 \\
2001 & 101 & 26 \\
2002 & 87 & 27 \\
2003 & 106 & 23 \\
2004 & 59 & 20 \\
2005 & 82 & 30 \\
2006 & 72 & 13 \\
2007 & 59 & 15 \\
2008 & 61 & 20 \\
2009 & 54 & 20 \\
2010 & 56 & 5 \\
2011 & 53 & 6 \\
\hline Total & 970 & 267 \\
\hline
\end{tabular}

Note. ${ }^{\text {an }}$ accident was defined by FAA Transportation

Definitions (1988), but was restricted to those events

where there was a chance it could have been prevented by

the pilots. (See also Figure 1.)

Table 2 provides a summary of the accident data by age and includes the number of accidents overall, the number of accident cases that had complete data (pilot age and total flight hours), the aggregate pilot hours by age, and the accident rate per 1,000 hours. The accident rate was based on the ratio of "the number of accident cases with complete data" and "aggregate pilot hours per age." This quotient was then multiplied by 1000 . From Table 2, note that although there were 267 accidents, only 170 (64\%) cases included both pilot age and total number of flight hours, which were needed to calculate accident rates. There also were 48 cases (18\%) with incomplete data because age and/or flight hours were not reported.

Overall, with the exception of two outliers (ages 25 and 62), the accident rates per 1000 flight hours ranged from .06 (age 39) to .26 (age 45), and the ages with the highest rates involved pilots in their 40s (ages 41, 42, 45, 46, 47, 49). Of the 267 cases examined, there were only three accidents that involved pilots older than 60 years old. As for the two outliers, both were easily explained. There were two accidents involving 25-year-old pilots, but neither case included the pilots' total flight hours and therefore the corresponding accident rate was 0 . Similarly, there was one accident involving a 62-year- 
old pilot. This pilot had a total of 2,000 flight hours, which is unusual for older pilots, and the combination of a single case with a small number of flight hours inflated the corresponding accident rate for this age group.

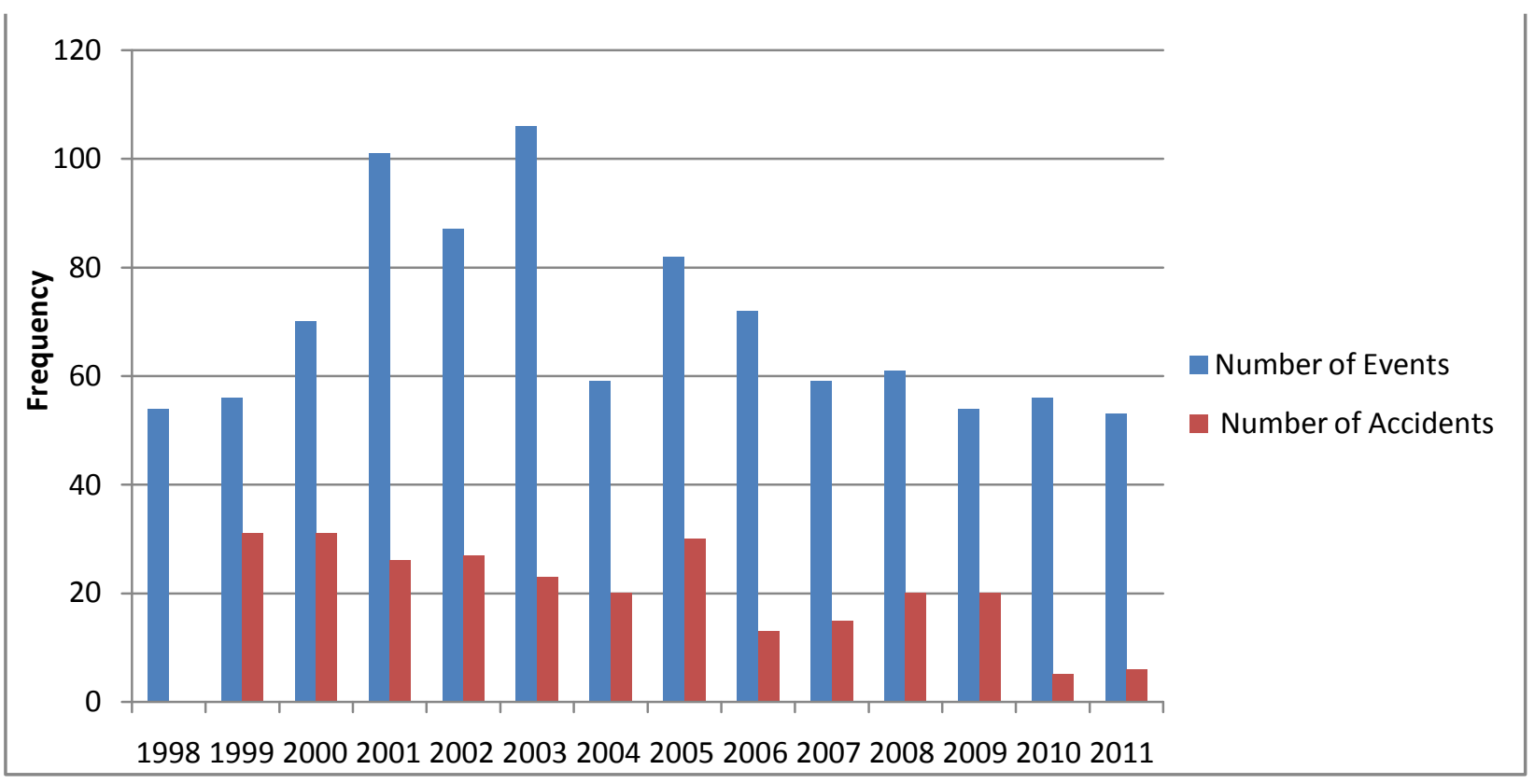

Figure 1. Number of events and accidents by year.

Table 3 compresses the data from Table 2 by summarizing the accident data by age group, which were partitioned into the following categories: less than or equal to 29 (LE29), 30-34, 35-39, 40-44, 45-49, 50-54, 55-59, 60-64, and Not Reported. These data also are pictorially displayed in Figure 2. An important attribute of Table 3 is the high percentage of incomplete data from the initial data set provided by ASIAS. For example, of the 267 accident cases that occurred during the targeted time period, 97 cases (36.3\%) did not include the pilot's age and/or the total number of flight hours.

The accident rates reported in Table 3 were calculated based on 10,000 pilot hours derived from the total flight hours. The accident rate ranged from 0.97 for the $50-54$ age group to 1.86 for the 60-64 age group. It should be noted, though, there were only three pilots in this latter group with an aggregate of 16,138 total flight hours. The accident rate steadily increased beginning with the 30-34 age group until the 45-49 age group where it peaked at 1.58. A dramatic drop was then observed with the 50-54 group and then increased again for the 60-64 age group.

Table 4 contains a summary of the number of accident cases involving pilots for which the initial ASIAS data set included corresponding ages. As reported in Table 4, 
pilots who were $26,40,42,44,48,52,54$, and 59 years old were involved in at least nine accidents during the 14-year period between 1998 and 2011; pilots of all other ages younger than 60 were involved in seven or fewer accidents. Pilots 60 years or older, though, were involved in two or fewer accidents during this time period.

\section{Preliminary Data Analyses}

Prior to testing our research hypothesis that pilot age is not related to aviation accident rates, we first conducted several preliminary analyses, including an outlier analysis, a check for multicollinearity, and a check for compliance with regression assumptions using the data set for accidents with complete cases reported in Table 2. This data set consisted of 39 cases involving 170 accidents. A brief description of each follows.

Outlier analysis. To check for outliers, we ran a Jackknife distance analysis involving pilots' age, total flight hours, and accident rate. This analysis flagged one outlier, which was the single case involving a 62-year-old pilot with an accident rate of 0.5 per 1000 flight hours. We removed this case, which left the data set consisting of 38 cases involving a total of 169 accidents.

Multicollinearity. We checked for multicollinearity by examining the variable inflation factors (VIFs) for the corresponding regression coefficients. According to Cohen, Cohen, West, and Aiken (2003), VIFs greater than 10 indicate the presence of multicollinearity. The VIFs obtained were 1.0.

Regression assumptions. We also examined the data set with respect to regression assumptions. According to Cohen et al. (2003), a given data set should be compliant with six regression assumptions: linearity, correct specification of the independent variables, measurement reliability, homoscedasticity of the residuals, independence of the residuals,

and normality of the residuals. Because we were considering only one factor, namely, pilot age, we did not examine the data set for correct specification of the independent variables or for measurement error. 
Table 2

Summary of Accident Data by Individual Ages

\begin{tabular}{|c|c|c|c|c|}
\hline Pilot Age & $\begin{array}{c}\text { Number of } \\
\text { Accident Cases }\end{array}$ & $\begin{array}{l}\text { Number of Accident Cases with } \\
\text { Complete Data }{ }^{\mathbf{b}}\end{array}$ & $\begin{array}{l}\text { Total Flight } \\
\text { Hours per Age }\end{array}$ & $\begin{array}{l}\text { Accident Rate per } \\
1,000 \text { Hours }^{\mathrm{c}}\end{array}$ \\
\hline 23 & 1 & 1 & 8,000 & 0.125 \\
\hline 24 & 2 & 1 & 12,518 & 0.0798849656 \\
\hline 25 & 2 & 0 & 0 & 0.0 \\
\hline 26 & 11 & 9 & 69,334 & 0.1298064442 \\
\hline 27 & 3 & 2 & 15,850 & 0.1261829653 \\
\hline 28 & 3 & 2 & 15,865 & 0.1260636621 \\
\hline 29 & 4 & 4 & 41,103 & 0.0973164976 \\
\hline 30 & 7 & 5 & 39,885 & 0.1253604112 \\
\hline 31 & 3 & 3 & 37,943 & 0.0790659674 \\
\hline 32 & 3 & 1 & 12,500 & 0.08 \\
\hline 33 & 2 & 2 & 14,850 & 0.1346801347 \\
\hline 34 & 4 & 3 & 22,785 & 0.1316655695 \\
\hline 35 & 7 & 7 & 32,678 & 0.214211396 \\
\hline 36 & 5 & 5 & 35,795 & 0.1396843135 \\
\hline 37 & 7 & 6 & 52,162 & 0.1150262643 \\
\hline 38 & 3 & 2 & 21,783 & 0.0918147179 \\
\hline 39 & 4 & 3 & 51,400 & 0.0583657588 \\
\hline 40 & 10 & 8 & 57,813 & 0.1383771816 \\
\hline 41 & 5 & 3 & 15,014 & 0.1998135074 \\
\hline 42 & 10 & 8 & 42,749 & 0.1871388804 \\
\hline 43 & 6 & 5 & 57,281 & 0.0872889789 \\
\hline 44 & 11 & 9 & 75,623 & 0.1190114119 \\
\hline 45 & 5 & 4 & 15,284 & 0.2617115938 \\
\hline 46 & 7 & 6 & 33,111 & 0.1812086618 \\
\hline 47 & 7 & 5 & 30,811 & 0.1622797053 \\
\hline 48 & 11 & 9 & 69,887 & 0.1287793152 \\
\hline 49 & 6 & 6 & 38,334 & 0.1565190171 \\
\hline 50 & 7 & 5 & 38,781 & 0.1289291148 \\
\hline 51 & 4 & 4 & 28,917 & 0.1383269357 \\
\hline 52 & 9 & 4 & 46,285 & 0.0864210867 \\
\hline 53 & 5 & 4 & 36,225 & 0.11042098 \\
\hline 54 & 12 & 8 & 70,301 & 0.1137963898 \\
\hline 55 & 6 & 6 & 39,696 & 0.1511487304 \\
\hline 56 & 5 & 5 & 43,854 & 0.1140146851 \\
\hline 57 & 5 & 1 & 9,145 & 0.1093493712 \\
\hline 58 & 5 & 5 & 46,446 & 0.1076518968 \\
\hline 59 & 9 & 6 & 63,882 & 0.0939231708 \\
\hline 61 & 2 & 2 & 14,138 & 0.1414627246 \\
\hline 62 & 1 & 1 & 2,000 & 0.5 \\
\hline Not Reported & 48 & & & \\
\hline Total & 267 & 170 & $1,362,578$ & \\
\hline
\end{tabular}

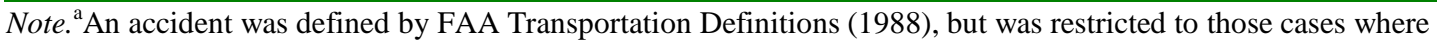
there was a chance it could have been prevented by the pilots. ${ }^{\mathrm{b}}$ This includes only cases in which pilot age and total number of flight hours were reported. 'Accident rate was calculated as ("Number of Accident Cases with Complete Data” divided by “Total Flight Hours per Age”) $\times 1000$. 
Table 3

Summary of Accident Data by Age Groups

\begin{tabular}{lccccc}
\hline Age Group & $\begin{array}{c}\text { Number } \\
\text { of } \\
\text { Accident } \\
\text { Cases }^{\mathbf{a}}\end{array}$ & $\begin{array}{c}\text { Number of } \\
\text { Accident Cases } \\
\text { with Complete } \\
\text { Data }^{\mathbf{b}}\end{array}$ & $\begin{array}{c}\text { \% Cases with } \\
\text { Incomplete } \\
\text { Data }\end{array}$ & $\begin{array}{c}\text { Total Flight } \\
\text { Hours per Age } \\
\text { Group }\end{array}$ & $\begin{array}{c}\text { Accident } \\
\text { Rate per } \\
\mathbf{1 0 . 0 0 0} \\
\text { Hours }^{\mathbf{c}}\end{array}$ \\
\hline LE29 & 26 & 19 & $26.9 \%$ & 162,670 & 1.17 \\
$30-34$ & 19 & 14 & $26.3 \%$ & 127,693 & 1.10 \\
$35-39$ & 26 & 23 & $11.5 \%$ & 193,818 & 1.19 \\
$40-44$ & 42 & 33 & $21.4 \%$ & 248,480 & 1.33 \\
$45-49$ & 36 & 30 & $16.7 \%$ & 189,977 & 1.58 \\
$50-54$ & 37 & 25 & $32.4 \%$ & 257,205 & 0.97 \\
$55-59$ & 30 & 23 & $23.3 \%$ & 203,023 & 1.13 \\
$60-64$ & 3 & 3 & $0 \%$ & 16,138 & 1.86 \\
Not & 48 & & & & \\
Reported & & & & & \\
\hline Total & 267 & 170 & $36.3 \%$ & $1,399,004$ & \\
\hline
\end{tabular}

Note. ${ }^{\mathrm{a}}$ An accident was defined by FAA Transportation Definitions (1988), but was restricted to those cases where there was a chance it could have been prevented by the pilots. ${ }^{\mathrm{b}}$ This includes only cases in which pilot age and total number of flight hours were reported. 'Accident rate was calculated as ("Number of Accident Cases with Complete Data” divided by “Total Flight Hours per Age Group”) × 10000 .

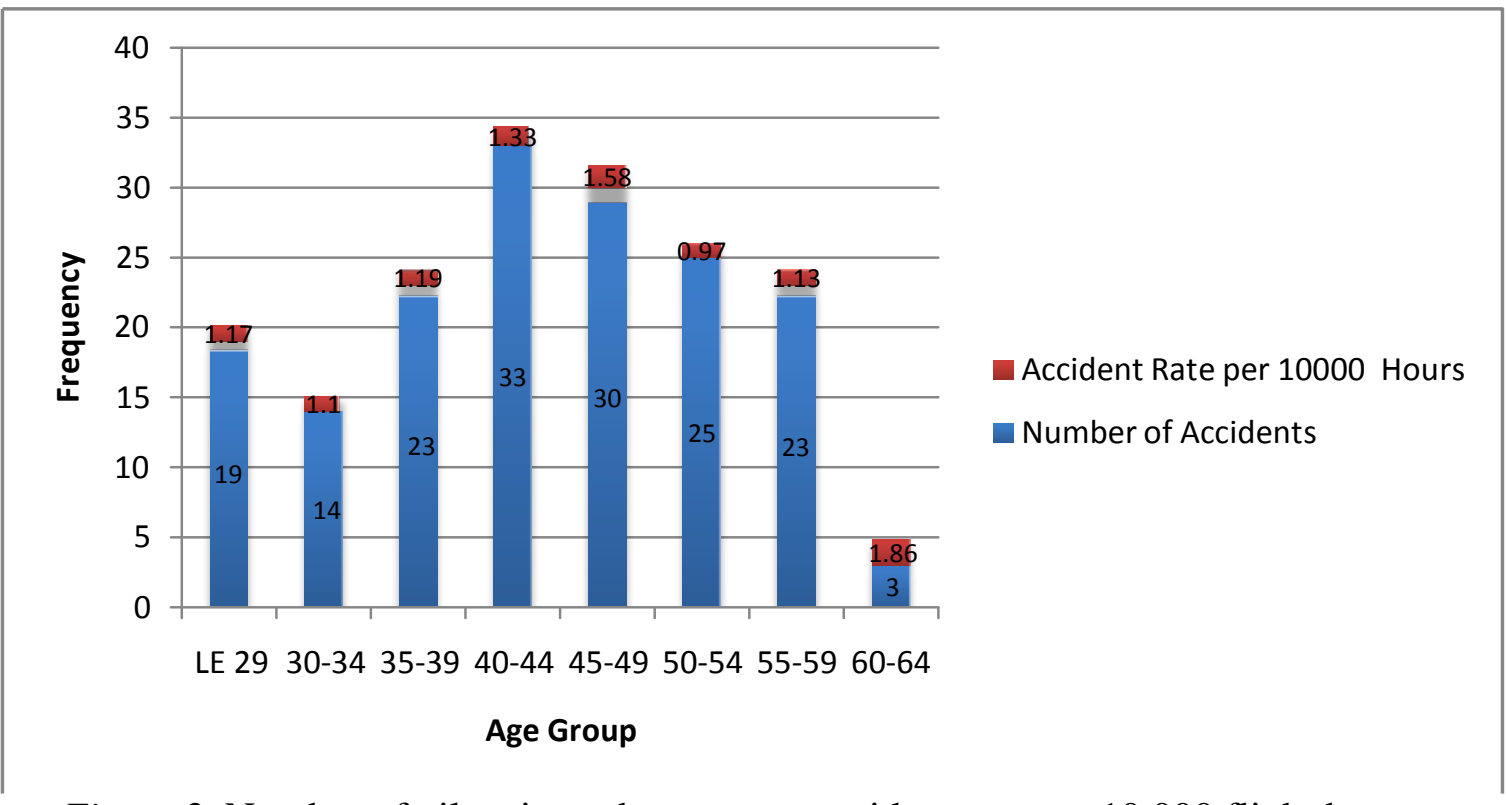

Figure 2. Number of pilots in each group vs. accident rate per 10,000 flight hours. 
Table 4

Summary of Accident Cases by Number of Pilots with Respect to Age

\begin{tabular}{cccc}
\hline Age in Years & Number of Pilots & Age in Years & Number of Pilots \\
\hline 23 & 1 & 43 & 6 \\
24 & 2 & 44 & 11 \\
25 & 2 & 45 & 5 \\
26 & 11 & 46 & 7 \\
27 & 3 & 47 & 7 \\
28 & 3 & 48 & 11 \\
29 & 4 & 49 & 6 \\
30 & 7 & 50 & 7 \\
31 & 3 & 51 & 4 \\
32 & 3 & 52 & 9 \\
33 & 2 & 53 & 5 \\
34 & 4 & 54 & 11 \\
35 & 7 & 55 & 6 \\
36 & 5 & 56 & 5 \\
37 & 7 & 57 & 5 \\
38 & 3 & 58 & 5 \\
39 & 4 & 59 & 9 \\
40 & 10 & 60 & 0 \\
41 & 5 & 61 & 2 \\
42 & 10 & 62 & 1 \\
\hline
\end{tabular}

Note. $N=267$. Of these 267 accident cases, 48 cases had missing age data.

Linearity and homoscedasticity of the residuals. To check for these two assumptions, we regressed accident rate on pilot age and examined a scatter plot of the residuals against the predicted values and included the zero-line. The result showed little systematic pattern in the plot. Although the corresponding lowess line did not converge exactly to the zero line, we judged it to be close enough to conclude there was constant variance of the residuals. Nevertheless, we were still concerned about the possible presence of a nonlinear relationship between the variables as cited in the literature. For example, Golaszewski (1983) reported a U-shaped relationship and Kay et al. (1994) reported a quadratic trend across age groups for aviation and automobile accident rates. Broach et al. (2003) also reported that a U-shaped function "best described the trend in mean accident rate across age group" (p. 29). As a result, we decided to run two separate regression analyses-bivariate linear and polynomial—with accident rate being regressed on age as well as on age-squared.

Independence of the residuals. To check for this assumption, we regressed accident rate on pilot age and examined a scatter plot of the residuals against the case numbers and included the zero-line. The result showed little systematic pattern in the plot. Although the corresponding lowess line did not converge exactly to the zero line, we judged it to be 
close enough to conclude there was no relationship among the residuals for any subset of cases in the analysis.

Normality of the residuals. To check for this assumption, we examined a normal q-q plot of the residuals. In a normal q-q plot, if the residuals ape a normal distribution, then they should appear to be close to the straight line that is superimposed. This was indeed the case, and all of the points were enclosed within a 95\% confidence band.

\section{Primary Data Analyses}

Working with a data set that consisted of 38 complete cases involving 169 accidents (see Table 2), we first conducted a bivariate linear analysis in which accident rate per 1000 hours was regressed on pilot age. This analysis yielded a nonsignificant model, $r^{2}=$ $.007, F(1,35)=0.26, p=.6127$ (see Table 5). Thus, based on the sample data, we failed to reject the corresponding null hypothesis: There is no significant linear relationship between pilot age and accident rate.

Table 5

Parameter Estimates for Linear Model of Accident Rate vs. Age

\begin{tabular}{lccccc}
\multicolumn{1}{c}{ Term } & Estimate & $\boldsymbol{S E}$ & $\boldsymbol{t}$ & $\mathbf{9 5 \%}$ CI & $\boldsymbol{p}$ \\
\hline Intercept & 0.1155 & 0.0272 & 4.24 & {$[0.060,0.171]$} & .0002 \\
Pilot Age & 0.0003 & 0.0006 & 0.51 & {$[-0.001,0.002]$} & .6127 \\
\hline \hline
\end{tabular}

Note. $N=169$ accidents with complete data involving 38 different pilot ages ranging from 29 to 61 years old (see Table 2). Overall $r^{2}=.0074, F(1,35)=0.26, p=.6127$.

We next conducted a quadratic analysis in which accident rate per 1000 hours was regressed on pilot age and age-squared. This yielded a nonsignificant overall model, $R^{2}=$ $.102, F(2,34)=1.93, p=.1601$ (see Table 6). Although the increment in explained variance $\left(s r^{2}\right)$ between the linear and quadratic models was $.102-.007=.095$, this increment also was not significant, $F(1,35)=3.687, p=.0630$. Thus, based on sample data, there is no significant quadratic relationship between pilot age and accident rate.

Table 6

Parameter Estimates for Quadratic Model of Accident Rate vs. Age

\begin{tabular}{lccccr}
\hline Term & Estimate & $\boldsymbol{S E}$ & $\boldsymbol{t}$ & $\mathbf{9 5 \%}$ CI & $\boldsymbol{p}$ \\
\hline Intercept & 0.1296 & 0.0273 & 4.74 & {$[0.074,0.185]$} & $<.0001$ \\
Pilot Age & 0.0003 & 0.0006 & 0.50 & {$[-0.001,0.001]$} & .6127 \\
(Pilot Age) $^{2}$ & -0.0001 & $6.8 \times 10^{-5}$ & -1.89 & {$[-0.000,0.000]$} & .0667 \\
\hline \hline
\end{tabular}


Note. $N=169$ accidents with complete data involving 38 different pilot ages ranging from 29 to 61 years old (see Table 2). Overall $R^{2}=.1021, F(2,34)=1.93, p=.1601$.

In addition to the previous analyses, we also examined the differences in accident rates among the nonoverlapping age groups used by Broach et al. (2003) as shown in Table 3. The results of a one-way ANOVA confirmed there were no significant differences in accident rates with respect to any of the targeted age groups, $R^{2}=.3121$, $F(7,29)=1.88, p=.1097$ (see Table 7). Thus, although the different age groups collectively accounted for $31.21 \%$ of the variance in accident rates, the overall model was not significant at the preset alpha level of .05.

Table 7

Mean Accident Tae per 1000 Hours by Age Group

\begin{tabular}{lcccc}
\hline Age Group & $\boldsymbol{N}^{\mathbf{a}}$ & $\boldsymbol{M}^{\mathbf{b}}$ & $\boldsymbol{S E}^{\mathbf{c}}$ & $\mathbf{9 5 \%} \mathbf{C I}$ \\
\hline LE29 & 6 & .11 & 0.015 & {$[.08, .14]$} \\
$30-34$ & 5 & .11 & 0.017 & {$[.08, .14]$} \\
$35-39$ & 5 & .12 & 0.017 & {$[.09, .16]$} \\
$40-44$ & 5 & .14 & 0.017 & {$[.11, .18]$} \\
$45-49$ & 5 & .18 & 0.017 & {$[.14, .21]$} \\
$50-54$ & 5 & .12 & 0.017 & {$[.08, .15]$} \\
$55-59$ & 5 & .12 & 0.017 & {$[.08, .15]$} \\
$60-64$ & 1 & .14 & 0.037 & {$[.06, .22]$} \\
\hline
\end{tabular}

Note. $N=169$ accidents with complete data involving 38 different pilot ages ranging from 29 to 61 years old (see Table 2).

${ }^{\mathrm{a}} N=$ total number of accident cases with complete data for each age group. ${ }^{\mathrm{b}} M=$ mean accident rate per 1000 flight hours. ${ }^{\mathrm{C}} \mathrm{SE}=$ standard error based on pooled estimate of error variance. Overall $R^{2}=.3121, F(7,29)$ $=1.88, p=.1097$.

\section{Discussion}

The results of the current study are consistent with those reported by Mohler et al. (1967), Broach (2000), and Li et al. (2003). There was no significant linear or quadratic relationship between pilot age and accident rate, and it appears that the accident rate of senior U.S. part 121 air carrier pilots is not statistically different than the accident rate of their younger counter parts. The results of the study are not consistent with those reported by Broach et al. (2003), however, who reported a significant quadratic relationship between age and accident rate. A plausible explanation for this inconsistency is that Broach et al.'s findings were based on data from 1988 to 1997, whereas the current 
study's findings were based on data from 1998 to 2011. A second plausible explanation is that the data set of the current study was incomplete. This also was a problem for Broach et al. who commented on the "limits of available data" (p. 13). It is conceivable that if we had a more complete data set, then the results might have been more consistent with those of Broach et al. It also is conceivable that if more data were available to Broach et al., then their findings might have been more consistent with ours. A third plausible explanation is that our analysis was based on a very restrictive definition of an "accident." It is possible that if we had examined all the event data and used FAA's definition of an accident without imposing an additional restriction on this definition that focused on only accidents that were due to pilot error, then we might have had similar results to those reported by Broach et al.

In conclusion, age does not appear to be a significant predictor of accident rates involving part 121 pilots for U.S. air carriers. Based on these results, a recommendation to the FAA is to remove the age 65 mandatory retirement regulation so part $121 \mathrm{U}$.S. air carrier pilots may operate an aircraft as pilots beyond the age of 65 as long as they can hold a valid class I or II medical certificate.

A final comment about the amount of missing data also is warranted. The number of missing data in the data set ASIAS provided surprised us. Because not all the cases reported by the NTSB included total flight hours and pilot age, any analysis that examines the relationship between pilot age and accident rate measured per flight hours is going to be problematic, which will make it difficult to compare results from different studies. Therefore, a recommendation is for the NTSB and FAA to strive for data completeness and integrity by ensuring that all the data are collected and included in their investigation reports.

\section{Limitations and Delimitations}

A limitation refers to circumstances or events that are beyond the control of the researcher. In the current study, one limitation was with respect to the data set. Because ASIA provided the data, we had no control over its integrity or accuracy. As noted above, second limitation is the amount of missing data.

A delimitation refers to circumstances or events that the researcher imposes on the study that further limits the generalizability of the results. One delimitation of the current study is that we only considered accident reports with respect to part 121 operations as defined by FAA Transportation Definitions (1988).Thus, a similar study to the current one that involves populations other than part 121 pilots such as general aviation pilots might not get the same results. A second delimitation is that we used a more restrictive definition of an accident than the FAA's definition. Accidents that are compliant with the criteria of C.F.R $\S 830.2$ but could not be prevented by the pilots (i.e., were not the result of pilot error) were not included. As a result, similar studies to the current one that removes the restriction we imposed might not get the same results. A third delimitation is 
that we chose to delete all cases with missing data. Therefore, another study that uses this data set but opts to use a data imputation method for missing data might not get the same results. 


\section{References}

Broach, D. (2000). Pilot age and accident Rates: A re-analysis of the 1999 Chicago Tribuner report and discussion of technical considerations for future analyses. Retrieved from http://www.faa.gov/library/reports/medical/age60/media/age60_2.pdf

Broach, D., Joseph, K. M., \& Schoreder, D. J. (2003). Pilot age and accident rates report 4: An analysis of professional ATP and commercial pilot accident rates by age. Retrieved from http://www.faa.gov/data_research/research/med.../age60/.../age60_4.pdf

Cohen, J., Cohen, P., West, S. G., \& Aiken, L. S. (2003). Applied multiple regression/correlation analysis for the behavioral sciences (3rd ed.). Mahawah, NJ: Lawrence Erlbaum.

FAA (2009). Part 121 pilot age limit, 14 CFR Parts 61 and 121. Federal Register, July 15, 74(134), 34229. Retrieved from http://www.regulations.gov/\#!documentDetail;D=FAA-2006-26139-6108

FAA Transportation Definitions, 49 C.F.R. § 830.2 (1988). Retrieved from http://www.ecfr.gov/cgi-bin/textidx?rgn=div5\&node=49:7.1.4.1.12\#49:7.1.4.1.12.1.1.2

Golaszewski, R.S. (1983). The influence of total flight time, recent flight time and age on pilot accident rates. (Tech.Rep. No.DTRS57-83-P-80750). Bethesda, MD: AcumenicsResearch and Technology.

International Brotherhood of Teamsters (2005). Federal aviation administration's age 60 rule. Retrieved from http://www.age60rule.com/docs/IBT_Submission_to_ARC_Panel.pdf

Kay, E. J., Hillman, D. J. Hyland, D. T., Voros, R. S., Harris, R. M., \& Deimler, J. D. (1994). Age60 rule research, Part III: Consolidated database experiments final report. (FAA-AM-92-22). Washington, D.C.: Federal Aviation Administration, Office of Aviation Medicine. Retrieved from: http://www.faa.gov.

Li, G., Baker, S. P., Grabowski, J. G., Qlang, Y., McCarthy, M. L., \& Rebok, G. W. (2003). Age, flight experience, and risk of crash involvement in a cohort of professional pilots. American Journal of Epidemiology, 157(10), 874-880.

Mohler, S. R., Bedell, H. S., Ross, A., \& Veregge, E. J. (1967) Aircraft accidents by older persons. Springfield: Federal Aviation Administration. NTIS Report Number FAA-AM-67-22. Retrieved from libraryonline.erau.edu/online-fulltext/faa-aviation-1medicine-reports/AM6722.pdf

National Transportation Safety Board (2011). Review of U.S. civil aviation accidents 2007-2009: Review of aircraft accident data. NTSB Report Number NTSB/ARA-11/01. National Technical Information Service Number PB2011113050. Retrieved from http://www.ntsb.gov/doclib/reports/2011/ara1101.pdf 